Results: A total of 90 RA patients (women, 83\%; mean age, 67.2 \pm 12 . years) were included. The median disease duration was 8.5 (interquartile range (IQR): $4.9,17$ ) years, the mean DAS28-ESR was $2.92 \pm 1.2$, and the median MTX dose was 10 (IQR: 8, 12) mg/week. Nineteen patients $(21 \%)$ used a biologic agent. There was a significant correlation between total hip BMD and bone mass $(r=0.64, p<0.001)$. The details are shown in Figure 1. Bone mass was significantly correlated with femoral neck BMD $(r=0.62, p<0.001)$, whole body BMD $(r=0.60, p<0.001)$, and lumbar BMD $(r=0.49, p<0.001)$. Bone mass was significantly lower by DEXA $(1.9$ $\pm 0.5 \mathrm{~kg})$ than by $\mathrm{BIA}(2.0 \pm 0.4 \mathrm{~kg})(\mathrm{P}<0.001)$.

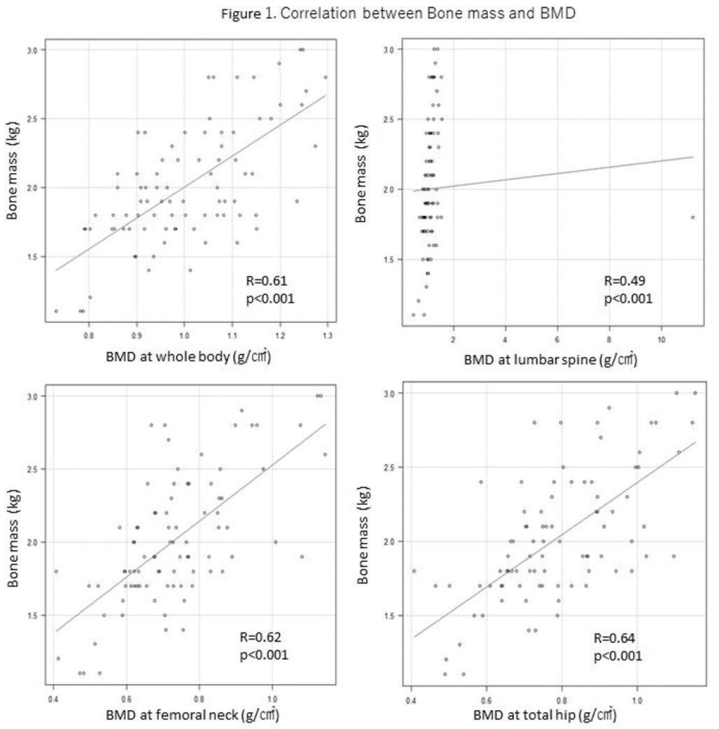

Figure 1

Conclusion: There was a significant correlation between bone mass by $B I A$ and BMD by DEXA. Bone mass by BIA and total hip BMD had the strongest correlation. Bone mass is likely to be overestimated by BIA. Thus, we need to evaluate it with appropriate caution.

Disclosure of Interests: Koji Mandai: None declared, Yutaro Yamada Speakers bureau: Abbvie, Chugai, Mitsubishi Tanabe, Tatsuya Koike Speakers bureau: AbbVie, Astellas Pharma Inc., Bristol-Myers Squibb, Chugai Pharmaceutical, Eisai, Janssen, Lilly, Mitsubishi Tanabe Pharma Corporation, MSD, Ono Pharmaceutical, Pfizer, Roche, Takeda Pharmaceutical, Teijin Pharma, and UCB, Tadashi Okano Speakers bureau: AbbVie, Noriaki Hidaka: None declared, Masahiro Tada Speakers bureau: Abbvie, Astellas Pharma, Bristol-Myers Squibb, Chugai Pharmaceutical, Eisai, Janssen Pharmaceutical, Mitsubishi Tanabe Pharma Corporation, Ono Pharmaceutical, Pfizer Japan, Takeda Pharmaceutical

DOI: 10.1136/annrheumdis-2019-eular.1486

\section{AB0337 IS THE RADIAL DEVIATION ASSOCIATED WITH MEDIAN NERVE SWELLING IN PATIENTS WITH RHEUMATOID ARTHRITIS?}

Başak Mansçz-Kaplan ${ }^{1}$, Seçil Vural ${ }^{2}$, Figen Ayhan' ${ }^{1}{ }^{1}$ University of Health Sciences, Ankara Training and Research Hospital, Physical Medicine and Rehabilitation, Ankara, Turkey; ${ }^{2}$ University of Health Sciences, Ankara Training and Research Hospital, Physical Medicine and Rehabilitation, Ankara, Turkey

Background: Rheumatoid arthritis (RA) and carpal tunnel syndrome (CTS) are known to be associated and also RA may lead to swelling of the median nerve without the presence of CTS.

Objectives: This study was conducted to test the hypothesis that one of the causes of this median nerve swelling may be radial deviation developing after wrist involvement of RA.

Methods: Of a total of 138 cases, 51 that met the inclusion criteria were included in the study. Electroneuromyography (ENMG) was performed on each patient and those with a CTS diagnosis were excluded from the study. Duruöz hand index, visual analog scale and painDETECT questionnaire was performed in clinical assesment. Radiographic measurements including radial inclination angle were performed with radiography. Using ultrasonography, the median nerve cross-sectional areas (CSAs) of the patients were measured from the four levels of the distal $1 / 3$ of the forearm, radioulnar joint, pisiform bone and hook of hamate, and the ulnar nerve CSAs were measured from the pisiform bone.

Results: The study completed with 102 hands of 51 patients. $27 \%$ of these RA patients without clinical and electrophysiological findings were diagnosed as CTS by ultrasonography. A negative correlation was found between the radial inclination (RI) and the median CSAs measured from the radioulnar joint $(R:-0.49 ; p: 0.00)$, the pisiform bone $(R:-0.45 ; p$ 0.00 ), and hook of hamate (R: $-0.60, p: 0.00)$. When the hands were divided into three groups according to the ranges of RI specified in the literature, the median nerve CSA was found to be significantly higher in the group with a low RI at these levels $(p<0.001)$.

Conclusion: The median nerve CSAs increased as the radial deviation increased in RA patients. The prevention of disease progression may prevent the increase in median nerve CSA by preventing deviations in patients with RA. And the development of CTS may also be prevented.

\section{REFERENCES}

[1] Yagci I, Akdeniz Leblecicier M, Mansiz Kaplan B, Ozturk Gokbakan D, Akyuz G. Sonographic measurements can be misleading for diagnosis carpal tunnel syndrome in patients with rheumatoid arthritis. Acta Reumol Port. 2016;41:40-4

[2] Joshua Broder. Diagnostic imaging for the emergency physician. Elsevier Healh Science. Philadelphia, 2011; page 783.

[3] Ito J, Koshino T, Okamoto R, Saito T. Radiologic Evaluation of the rheumatoid hand after synovectomy and extensor carpi radialis longus transfer to extensor carpi ulnaris. J Hand Surg Am. 2003:28(4):585-90.

[4] Hammer BH, Hovden IA, Haavardsholm EA, Kristian Kvien T. Ultrasonography shows increased cross-sectional area of the median nerve in patients with arthritis and carpal tunnel syndrome. Rheumatology (Oxford) 2006:45(5):584-588.

[5] Hammer BH, Haavardsholm EA, Kristian Kvien T. Ultrasonographic measurement of the median nerve in patients with rheumatoid arthritis without symptoms or signs of carpal tunnel syndrome. Ann Rheum Dis. 2007;66:825-7

[6] Sakthiswary R, Singh R. Has the median nerve involvement in rheumatoid arthritis been overemphasized? Rev Bras Reumol. 2017;57(2):122,128.

Disclosure of Interests: None declared

DOI: 10.1136/annrheumdis-2019-eular.971

\section{AB0338 ELDERLY ONSET RHEUMATOID ARTHRITIS AND POLYMYALGIA RHEUMATICA: COMPARATIVE CLINICAL STUDY}

Melania Martínez-Morillo, Águeda Prior-Español, Anahy Brandy-Garcia, Susana Holgado Pérez, María Aparicio-Espinar, Laia Gifre, Anne Riveros-Frutos,

Clara Sangüesa-Gomez, Jordi Camins-Fàbregas, Ivette Casafont-Solé,

Annika Nack, Alejandro Olive, Lourdes Mateo Soria. Hospital Universitari Germans Trias i Pujol, Rheumatology, Badalona, Spain

Background: Polyarthritis at the elderly people usually has a similar onset with an acute inflammatory character and scapular girdle involvement. Differentiating elderly onset rheumatoid arthritis (EORA) and polymyalgia rheumatica (PMR) can be a diagnostic challenge.

Objectives: To analyse the clinical and analytical differences between EORA and PMR.

Methods: Longitudinal observational study of patients older than 60 years newly diagnosed with EORA (ACR/EULAR 2010) and PMR (ACR/EULAR 2012). Inclusion: consecutive and voluntary. Follow-up time: 12 months. A single rheumatologist made all follow-up visits. The clinical-epidemiological and analytical characteristics were collected. The statistical study was performed with Stata 15.1 .

Results: 45 EORA were recruited (53\% women; mean age $74.8 \pm 7.5)$ and 20 PRM ( $85 \%$ women; mean age $76.6+5.0$ ).

$75 \%$ of EORA had scapular girdle involvement, but only $44 \%$ of the pelvic girdle. All had peripheral arthritis, and the small joints of the hands were involved in $93.3 \%$, with edema in $46.7 \%$. Forty percent of EORA patients were seropositive (RF> $20 \mathrm{IU} / \mathrm{mL}$ and/or ACPA> $20 \mathrm{U} / \mathrm{mL}$ ): $33 \%$ RF positive (132.8 $\pm 126 \mathrm{IU} / \mathrm{mL}), 28.9 \%$ for ACPA (2 cases [15.4\%] from 100 to $250 \mathrm{U} / \mathrm{mL}$ and 11 cases [84.6\%] above $250 \mathrm{U} / \mathrm{mL}$ ) and in 10 patients [22.2\%] double positive). All patients with PMR patients had shoulder girdle involvement and $90 \%$ of the pelvic girdle. None of them had peripheral arthritis. RF was positive in one patient $(73 \mathrm{IU} / \mathrm{mL})$ and ACPA in 2 patients (titers between 20-40 U/mL). No patient was double positive. Table 1 and 2 . 